\title{
Pakistan calls for new international institutions
}

PAKISTAN's draft country paper for the UN Conference on Science and Technology for Development has now been circulated to various science bodies in Pakistan by the Ministry of Science and Technology. The 35-page document is a result of a long debate among the various scientific associations and government agencies in Pakistan, so the final version of the paper will probably not differ significantly from the views expressed in the draft, which lays great stress on international cooperation.

The UNCSTD conference has three main points on its agenda:

- Science and technology for development;

- Institutional arrangements and new forms of international cooperation in the application of science and technology;

- Utilisation of the existing UN system and other international organisations.

The draft has reviewed these issues as they affect Pakistan and the rest of the world, and has made some concrete proposals for improvement.

Pakistan, like most developing countries, faces great internal social disparities. So far the development pattern has been such that the elite and the urban areas have gained more than their due share, while the rural and the depressed sections have been relatively deprived from such benefits. The result has been great social unrest. But the country is striving to create a new socio-economic order wherein the benefits of development should be available to all.

The draft country paper distinguishes five priorities: water management; industrialisation; scientific and technological manpower; natural resources; and energy. These are rated as the most crucial for Pakistan. The draft also discusses technology transfer, the better utilisation of technical knowledge, and new science and technology.

Pakistan's experience of technology transfer has been far from satisfactory. Such transfer has mostly been through licensing or through joint ventures; direct investments have been rare. Technology transfers have largely been package deals on a turnkey basis. Such horizontal transfer is capital intensive (in foreign exchange), labour saving, and ultimately does not lead to grass roots development. Further, restrictive clauses in technology-transfer contracts - such as restrictions on exports, on the pattern of production, and so on, have held back proper and rapid development. In the distribution of licence agreements, the emphasis has been on consumer goods, to the detriment of capital equipment. The draft puts forward a number of suggestions to correct this imbalance.

So the draft makes a proposal that aid from UN and other international organisations should be made available to set up institutions for technology assessments which could assist local entrepreneurs in making a proper choice of technologies and in negotiating more reasonable terms in licensing agreements.

Some other significant points in the draft are:

Institutional arrangements for irrigation and water management are weak. Existing irrigation research institutes need strengthening in manpower as well as equipment through the help of international bodies. There should be international assistance in using sophisticated techniques like remote sensing from space for better water manage- priorities is needed at the global, regional and project level by the UNDP Technical Assistance Programme. A fund should be set up by UNDP for financing and strengthening the Technical Cooperation among Developing Countries (TCDC)".

The developed countries should "also be urged to contribute their due share of at least $0.3 \%$ of their GNP towards UNDP. In addition, developing countries with per capita income of more than $\$ 400$ may also be asked to contribute to this fund".

The draft continues: "in devising the mechanisms for future international cooperation, the paramount consideration should be the principles on which the Declaration of the Establishment of a New International Economic Order is based. Following from these, the major thrust for international cooperation and concerted

\section{Sorry, for copyright \\ reasons some images on this page may not be available online}

\section{Proper water management is a priority}

ment.

Technically trained and reliable manpower in fields like electronics, metallurgy, industrial design, petrochemicals, nuclear technology is lacking. To rectify this there should be increased international support to universities in such disciplines.

Exploitation of natural resources, particularly in mining and agricultural sectors is very weak. Institutions in these sectors need international support for R\&D.

Regional collaboration ought to be encouraged among developing countries in non-conventional energy technology, since it is likely to be a common factor in the economic development of the whole equatorial and sub-equatorial belt.

Scientific and technological research calls for a heavy investment of capital and human resources, and no developing country can mobilise them on the required level. International cooperation is essential. Individual countries have entered into bilateral agreements with friendly countries or have formed regional cooperative bodies but a "major shift in the emphasis and action will be to assist the developing countries in achieving a large measure of technological self-reliance through the building up of adequate indigenous science and technology capabilities for solving their problems of development and for working out a system through which they can benefit from each others capabilities and expertise, reducing dependence on developed countries."

As a corollary, it has been suggested that a network of cooperative institutions must be set up in the developing countries to promote a joint research effort on common problems. Some of these institutions with exceptional potential should be graded as "centres of excellence" to be supported by the UN.

The communication of scientific information also needs to be overhauled, says the draft. There should be a single focal point at the UN level instead of the multiplicity of different UN agencies each providing their own information. Private institutions should also be encouraged to provide information on their technologies.

Azim Kidwai 